McCartney, J.S., Zornberg, J.G., and Swan, R.H. (2005). "Effect of Geomembrane Texturing on GCL-Geomembrane Interface Shear Strength." Waste Containment and Remediation. ASCE Geotechnical Special Publication No. 142, Alshawabkeh, Benson, Culligan, Evans, Gross, Narejo, Reddy, Shackelford, and Zornberg (Editors), Austin, Texas, January (CD-ROM).

\title{
Effect of Geomembrane Texturing on GCL - Geomembrane Interface Shear Strength
}

\author{
John S. McCartney ${ }^{1}$ and Jorge G. Zornberg ${ }^{1}$ and Robert H. Swan ${ }^{2}$ \\ ${ }^{1}$ Department of Civil Engineering, Geotechnical Research Group, The University of \\ Texas at Austin, 1 University Station C1792, Austin, TX 78712-0280, PH (512) \\ 232-3595, FAX (512) 471-6548, EMAIL: zornberg@ mail.utexas.edu \\ ${ }^{2}$ SGI Testing Services, 4405 International Boulevard, Suite-B117, Norcross, Georgia \\ 30093, PH 1-866-SGI-LAB1, FAX 1-404-705-9300, EMAIL: \\ Testing@interactionspecialists.com
}

\section{ABSTRACT}

This study investigates the impact of geomembrane texturing on the peak and largedisplacement shear strength of the GCŁ GM interface using a significant commercial database of large-scale direct shear test results. Texturing procedures used by different GM manufacturers were found not to influence GCL-GM interface shear strength. GM texturing, quantified by asperity heights, was found to be highly variable. GM texturing was generally found to improve both the peak and largedisplacement shear strength of GCL-GM interfaces. The existence of an optimum asperity height beyond which there is a decrease in large-displacement shear strength was evaluated. The available data indicates that, at least for unhydrated GCL-GM interfaces, an optimum asperity height can be identified.

\section{INTRODUCTION}

Use of geomembranes (GMs) directly above a geosynthetic clay liner (GCL) in hydraulic barrier systems such as landfill covers or bottom liners has led to significantly improved hydraulic performance over the use of single GMs and single compacted clay layers. Stability is a major concern for side slopes in bottom liner or cover systems that include GCLs and GMs because of the low GCL internal shear strength (Zornberg et al. 2004) as well as the low GCŁ GM interface shear strength 
(McCartney et al. 2002; Triplett and Fox 2001). In this last case, hydrated sodium bentonite has been reported to extrude from the GCL leading to a lubrication of the interface.

When GCL-GM interfaces are subject to a constant shear displacement rate, they reach a peak shear strength value, followed by a decrease in shear strength at larger displacements. McCartney et al. 2002 observed that the GCL-GM interface reaches effectively constant large-displacement shear strength after approximately $50 \mathrm{~mm}$ of shearing in the direct shear device (typically less than a $2 \mathrm{kPa}$ decrease from $50 \mathrm{~mm}$ to $60 \mathrm{~mm}$ of displacement), although the residual shear strength is not necessarily reached until larger displacements. Different positions have been defended recently over the appropriateness of selecting peak or large-displacement shear strength values for design (Koerner and Bowman 2003; Gilbert 2001). GM texturing is often used to increase the peak shear strength of GCL-GM interfaces, and recent studies have found that it leads to an increase in the shear interaction between the GCL and the GM using asperity heights (Ivy 2003) and post-failure examination (Triplett and Fox 2001). However, data is limited, and the effect of texturing on the large-displacement shear strength has not been investigated. Due to waste settlement and other timedependent deformation mechanisms, the long-term shear strength of GCL-GM interfaces is likely to be governed by the shear strength at large displacements (i.e., greater than $50 \mathrm{~mm}$ ). This paper evaluates the results in a large database of shear strength results to quantify the effect of GM texturing on both the peak and largedisplacement GCL-GM interface shear strength. Specifically, this study investigates GCL-GM interface shear strength tests conducted using the same GCL, while considering the impact of GM texturing types, GM texturing asperity heights, and GCL conditioning procedures.

\section{DATABASE}

Data Source. Large-scale direct shear tests in the database used as a source for this study (GCLSS) were performed between 1997 and 2003 by SGI Testing Services (SGI), formerly the Soil-Geosynthetic Interaction laboratory of GeoSyntec Consultants. SGI is an accredited testing facility. It should be noted that procedures 
used for all GCŁ GM interface direct shear tests are consistent with ASTM D6243 (ASTM 1998), even though this standard was only approved in 1998. Most tests in the GCLSS database were conducted for commercial purposes and, consequently, the test characteristics and scope was defined by project-specific requirements.

Materials. Direct shear test results in the GCLSS database include tests on a single needle-punched GCL commercially known as Bentomat DN, referred herein as GCL $H$. GCL $H$ consists of a bentonite layer between two nonwoven carrier geotextiles, reinforced by pulling fibers from one of the carrier geotextiles through the other geotextile using a needling board. The fiber reinforcements are typically left entangled on the surface of the top carrier geotextile. McCartney et al. (2002) found that the internal and interface shear strength of GCL $H$ was among the highest of the GCLs tested, making it suitable for applications requiring high shear strength. The interfaces between the nonwoven carrier geotextile of the GCL and GMsfrom three manufacturers were tested. The GM manufacturers include Agru Microspike ${ }^{\circledR}$, referred to as GM $q$; GSE ${ }^{\circledR}$, referred to as GM $s$; and Polyflex ${ }^{\circledR}$, referred to as GM $u$. All of the GMs are textured HDPE. A structuring process during extrusion was used to form surface texturing for GM $q$, while co-extrusion of nitrogen gas through the molten polyethylene was used for GMs $s$ and $u$ to form asperities on the surface of the GM during cooling. The formation of texturing is an inherently variable process (Ivy 2003), so texturing variability is expectedacross a GM roll area.

Testing Equipment and Procedures. Large-scale direct shear devices with top and bottom shear boxes with dimensions of $305 \mathrm{~mm}$ by $305 \mathrm{~mm}$ in plan and $75 \mathrm{~mm}$ in depth were used in this study. A constant $S D R$ was applied to the bottom shear box using a mechanical screw drive system and the resultant shear load was measured on the top shear box using a load cell. Fig. 1(a) shows the configuration of the direct shear equipment used for GCL-GM interface shear strength testing, and Fig. 1(b) shows a detail of the specimen confinement.

The conditioning procedures for the GCL include hydration and consolidation of the GCL under project-specific normal stresses for project-specific time periods. The 
typical hydration process used in this study is a two-stage procedure in which GCL specimens were placed under a specified hydration normal stress $\left(\sigma_{\mathrm{h}}\right)$ outside the direct shear device and soaked in tap water during the specified hydration time $\left(t_{h}\right)$. The hydration normal stress, $\sigma_{\mathrm{h}}$ was often specified to equal the shearing normal stress $\left(\sigma_{n}\right)$. In this case, shearing was conducted immediately after hydration at a constant shear displacement rate (SDR). The same value of $\mathrm{SDR}=1.0 \mathrm{~mm} / \mathrm{min}$ was used for all tests in this study. The peak shear strength $\left(\tau_{\mathrm{p}}\right)$ and large displacement shear strength $\left(\tau_{\mathrm{ld}}\right)$ were recorded. However, if a $\sigma_{\mathrm{h}}$ smaller than the $\sigma_{\mathrm{n}}$ was specified, pore pressures were allowed to dissipate during a consolidation period $\left(\mathrm{t}_{\mathrm{c}}\right)$ before shearing. Additional details on the testing procedures are presented by McCartney et al. (2002).
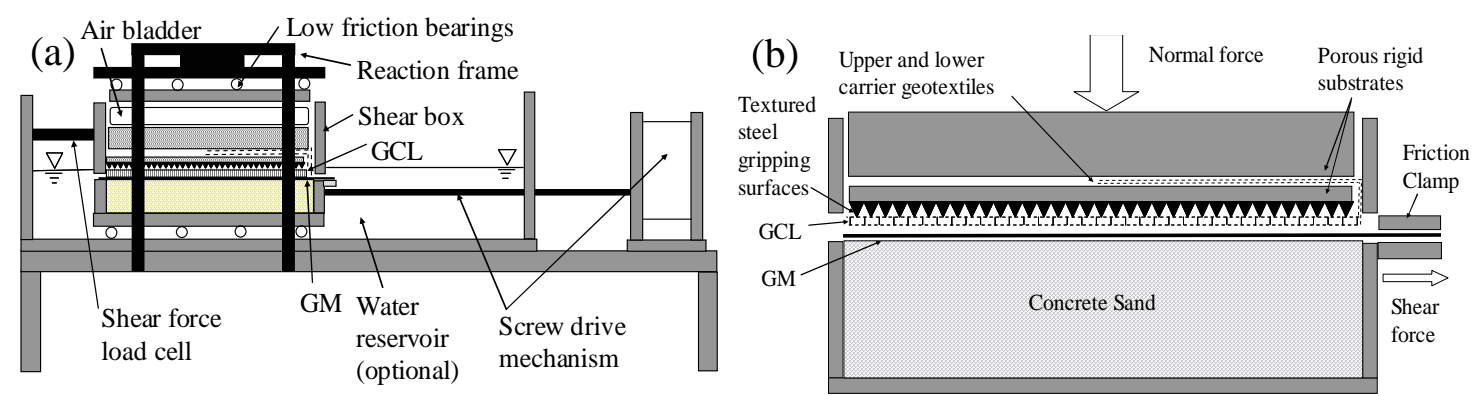

Fig. 1. Direct shear device: (a) Load application configuration; (b) Specimen detail

To quantify the texturing of the GM, asperity height measurements were conducted on GM specimens tested after 2002. Test method GRI GM12 (GRI 1999) was used to measure the asperity heights. This test involves placement of a dial gauge at the tip of an asperities, and measuring the change in height from the tip to the lowest point surrounding the tip. This procedure is repeated at 10 locations equally spaced across the roll width.

\section{OVERALL GCL GM INTERFACE SHEAR STRENGTH ANALYSIS}

The results peak and large-displacement shear strength values for interfaces between GCL $H$ and different GMs are presented in Fig. 2. Significant scatter of peak and large-displacement shear strength values is observed in these results. Several GCL and GM characteristics may affect GCL-GM interface shear strength, 
leading to the scatter observed in Fig. 2. Specifically, McCartney et al. (2002) found that the GCL carrier geotextile type, GCL internal reinforcement type, GCL conditioning procedures $\left(t_{h}, \sigma_{h}\right.$, and $\left.t_{c}\right)$, GM polymer type, and GM manufacturer affect the GCL-GM interface shear strength, while the GM thickness did not have a significant effect. In addition, McCartney et al. (2004) found that GCL-GM interface shear strength results show significant variability (coefficient of variation in peak shear strength of approximately 0.15 for different-lot specimens). This paper focuses mainly on interfaces between textured HDPE GMs and a needle-punched GCL with nonwoven carrier geotextile. Consequently, the variables affecting shear strength results to be evaluated herein are GM texturing types, GM asperity heights, and GCL conditioning.

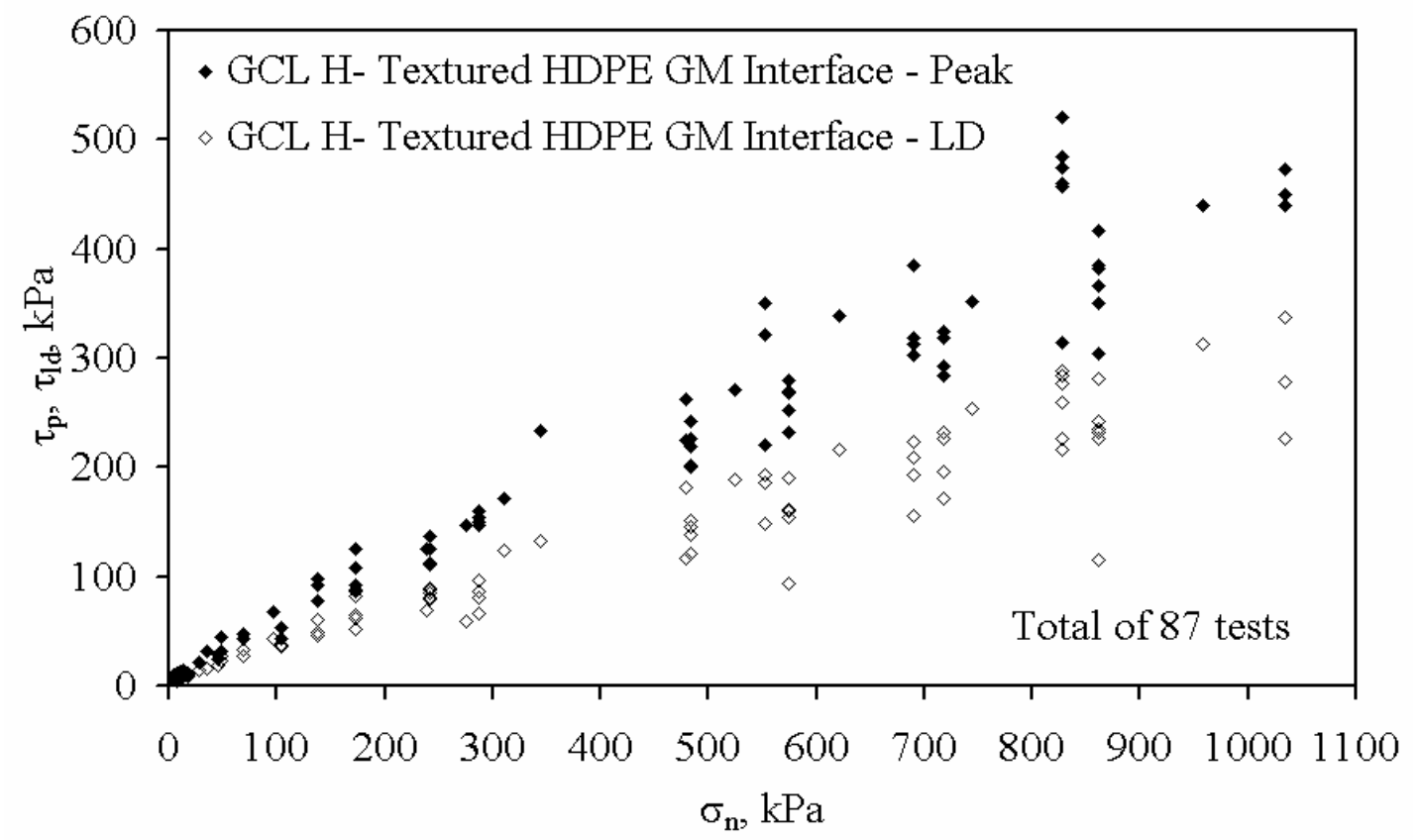

Figure 2: GCL-GM interface shear strength results

Figures 3(a) and 3(b) show the same data presented in Fig. 2 but grouping the results according to the GM texturing types (structured GM $q$ and co-extruded GMs $s$ and $u$ ). Although the texturing application selected by the different manufacturers is different, the results in this figure show no apparent effect of different GM manufacturing processes on GCL-GM interface shear strength. This suggests that variability within the GM texturing of each product line (asperity height) and GCL conditioning may more significantly impact the GC£ GM interface shear strength. 
(a)

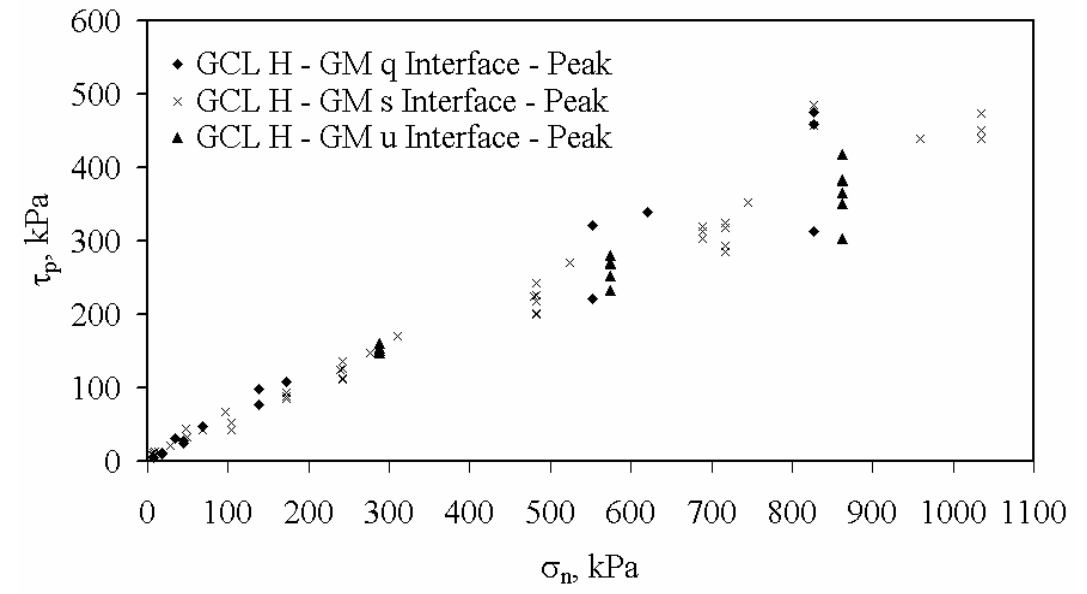

(b)

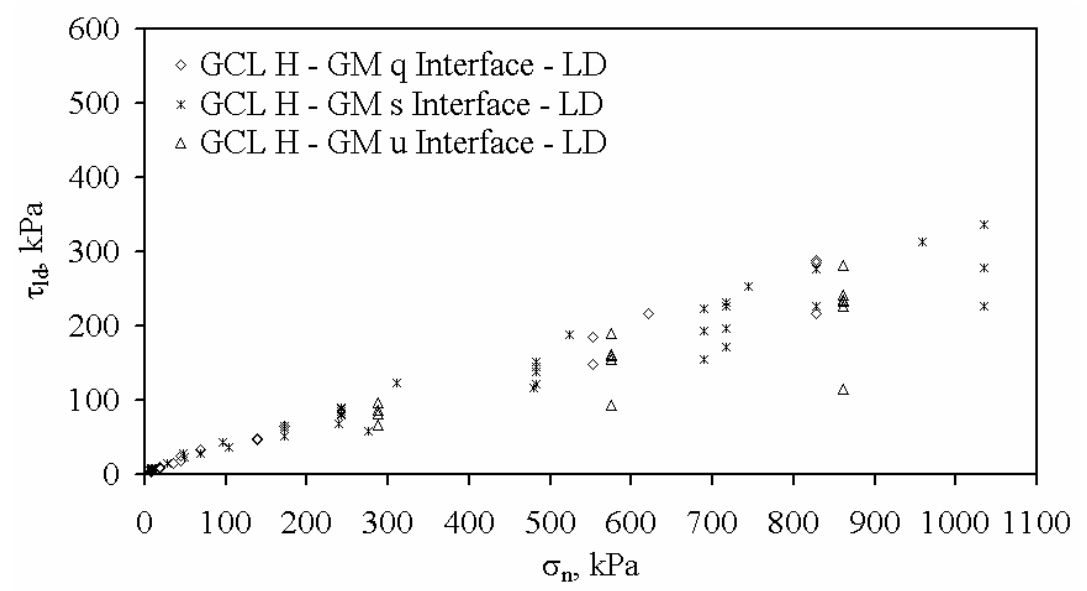

Figure 3: Effect of GM manufacturer: (a) Peak; (b) Large-displacement

\section{ASPERITY HEIGHT MEASUREMENTS}

Figures 4(a), 4(b), and 4(c) show the asperity height measurements for GMs $q, s$, and $u$, respectively. Several rolls of different thickness from each manufacturer were tested. Ten measurements were obtained at equal spacing across the roll widths. The average and standard deviation asperity height for each roll is presented. The three GMs have similar ranges of asperity heights (10 to 30 mils), and show some variability across the roll width (standard deviations between 0.8 and 2.8 mils). Fig. 4(d) shows a frequency density diagram for all of the asperity height measurements for the GMs tested. GM $q$ has regular, structured texturing, so there were many specimens with asperity heights around 20 and 30 mils. The two GMs with coextruded texturing (GMs $s$ and $u$ ) have a wider range of asperity heights. There were a large number of GM $s$ specimens with small asperity heights (less than 20 mils) and a large number of GM $u$ specimens with high asperity heights (more than 20 mils). 
This confirms the observation by Ivy (2003) that co-extruded GMs have high texturing variability.
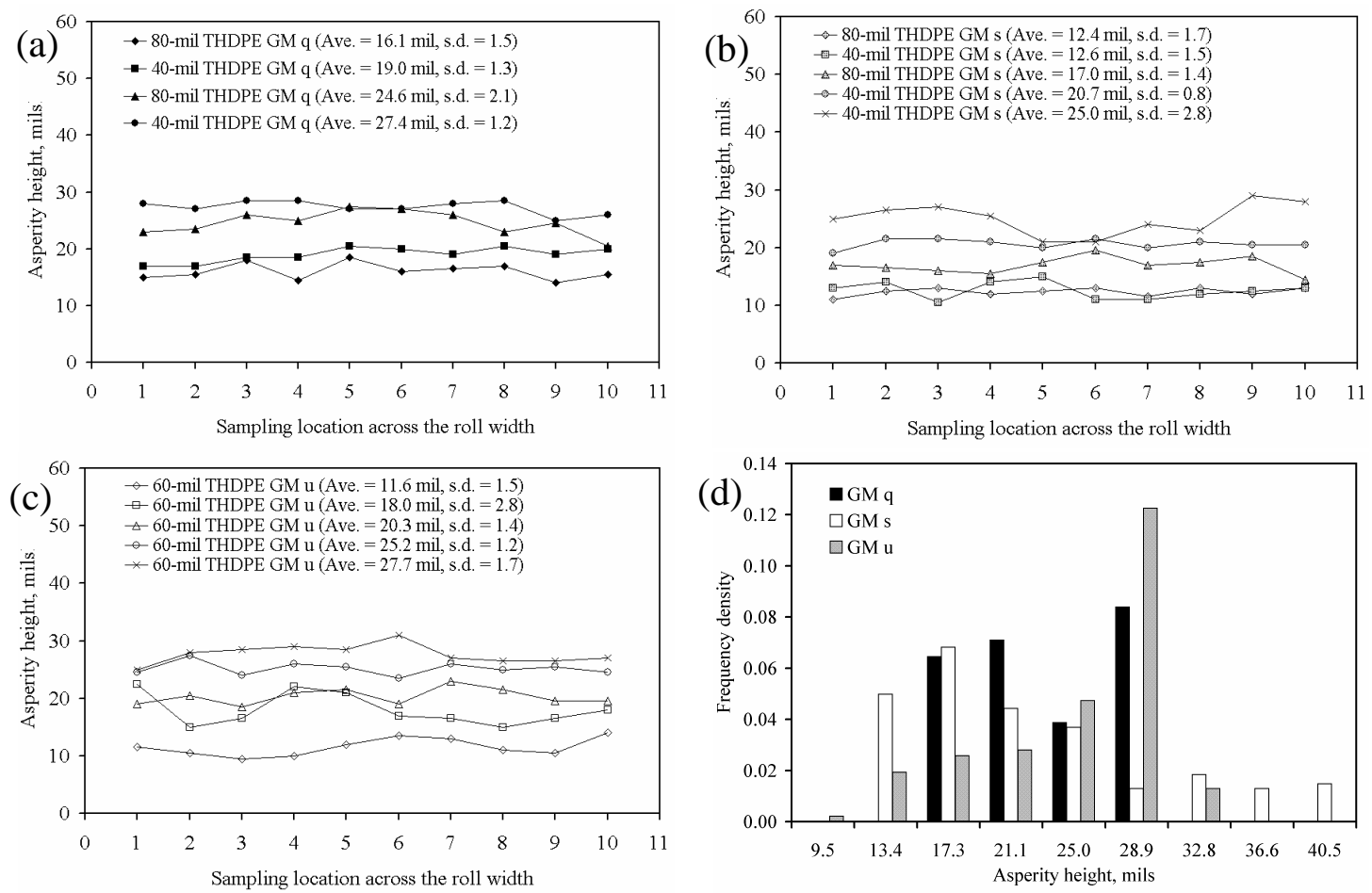

Figure 4: Asperity height variation across the width of GM rolls: (a) GM q; (b) GM s; (c) GM u; (d)

Frequency density distributions for all three GM manufacturers

\section{IMPACT OF GM TEXTURING ON GCL-GM INTERFACE SHEAR STRENGTH}

Fig. 5 shows the effect of asperity height on the interface shear strength between an unhydrated GCL and a textured GM $s$. The interfaces in this figure were tested under the same normal stress $\left(\sigma_{\mathrm{n}}=827.4 \mathrm{kPa}\right)$, and the large-displacement shear strengths were measured at a displacement of $75 \mathrm{~mm}$ for all tests. As these interfaces are unhydrated, the shear strength differences are primarily due to interaction between the textured asperities and the geotextile. The peak shear strength is observed to increase linearly with the asperity height. However, the GM specimen with an asperity height of 17 mils showed the smallest post-peak shear strength loss (i.e., the highest large-displacement shear strength), of the four GMs tested (asperity heights ranging from 13 mils to 25 mils). Although data is limited, this may suggest that there is an optimum asperity height beyond which there is no longer improvement in post-peak behavior for unhydrated GCL interfaces (17 mils for $\left.\sigma_{\mathrm{n}}=827.4 \mathrm{kPa}\right)$. 


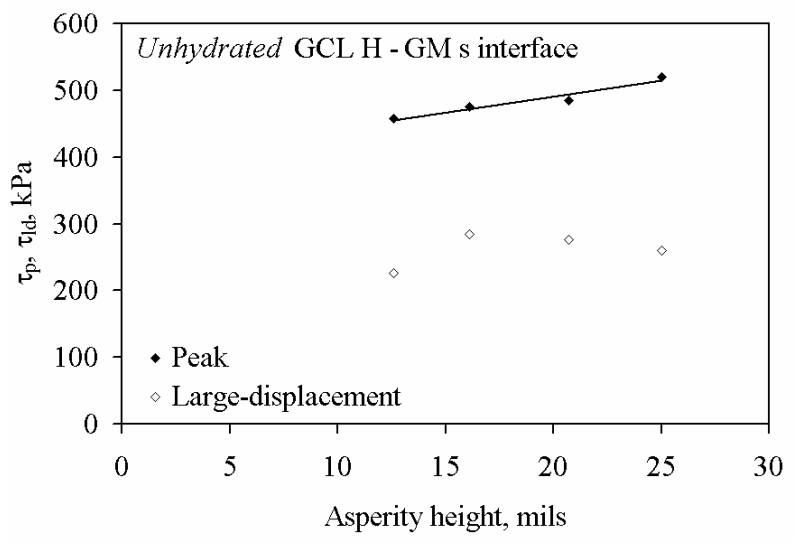

Figure 5: Effect of asperity height on unhydrated GCL $H$-HDPE GM $s$ interface shear strength

Fig. 6 shows the influence of GM asperity height on the shear strength of the interface between a clay soil and a textured GM $s$. In the situation that a large amount of bentonite extrudes from the GCL into the GCL-GM interface, the shear strength of the interface may be influenced more by the bentonite than by interaction between the GM asperities and GCL carrier geotextile. In spite of the limited range of asperity height values, the results show increasing interface peak and large-displacement shear strength with asperity height in clay soil-GM interfaces, especially under high $\sigma_{\mathrm{n}}$.

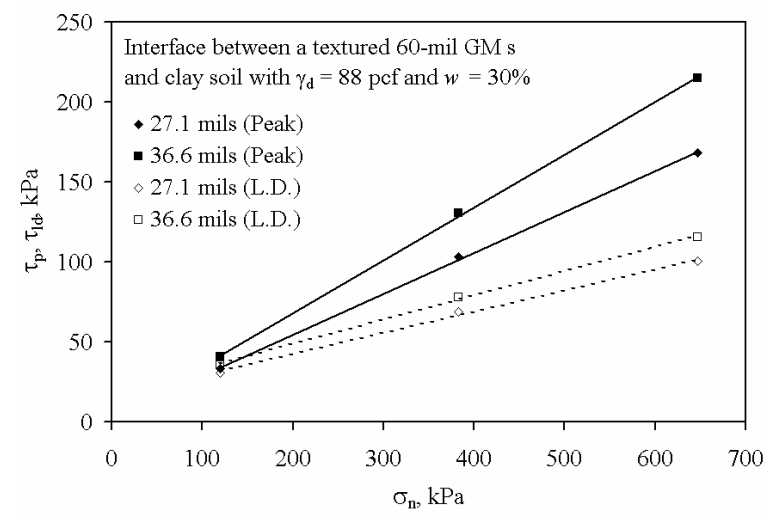

Figure 6: Effect of asperity height on clay soil-HDPE GM s interface shear strength

Fig. 7 shows the effect of conditioning on GCL-GM $q$ interface shear strength for specimens with constant asperity height. Conditioning involved hydration for $48 \mathrm{hs}$ at a hydration normal stress $\sigma_{\mathrm{h}}$ of $68 \mathrm{kPa}$ followed by a consolidation period under the corresponding shearing normal stress $\sigma_{\mathrm{n}}$. The hydrated specimens showed significantly lower peak and large-displacement interface shear strength, especially 
under high $\sigma_{\mathrm{n}}$. McCartney et al. (2002) suggests that this is due to increased bentonite extrusion from the GCL during hydration, consolidation and shearing.

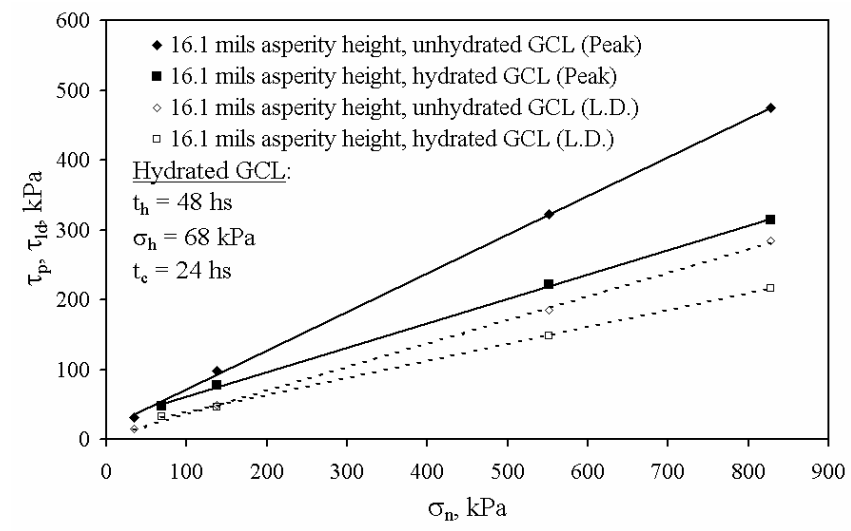

Figure 7: Effect of conditioning on GCL-GM $q$ interface shear strength

Fig. 8 shows the combined effect of asperity height and GCL conditioning procedures on the GCL-GM $u$ interface shear strength. The data in Fig. 8(a) shows a negligible effect of GM asperity height on GCL-GM peak and large-displacement interface shear strength for GCLs hydrated under the shearing normal stress $\left(\sigma_{\mathrm{h}}=\sigma_{\mathrm{n}}\right)$. However, this is expected due to the narrow range of asperity heights (26 to 28 mils) of the tested GMs. Fig. 8(b) shows that the effect of GM asperity height on interface shear strength is more substantial when GCLs are hydrated under free-swell conditions $\left(\sigma_{\mathrm{h}}=0 \mathrm{kPa}\right)$ and subsequently consolidated under the shearing normal stress. Unlike the results in Fig. 5, GMs with a low asperity height of 18 mils showed the lowest peak and large-displacement shear strength, with an increasing asperity influence with increasing $\sigma_{\mathrm{n}}$. Higher asperity heights (25 and 28 mils) led to higher peak and large-displacement shear strength. The GM interfaces with GCLs hydrated under $\sigma_{\mathrm{h}}=\sigma_{\mathrm{n}}$ [Fig. 8(a)] showed higher peak and large-displacement shear strength than those with GCL hydrated under free swell conditions [Fig. 8(b)]. This is attributed to increased bentonite extrusion from the GCL during free swell. The limited range of asperity heights in the interface shear strength results available for clay-GM and hydrated GCL-GM data sets does not allow an evaluation of the existence of an optimum asperity height for these interfaces. 

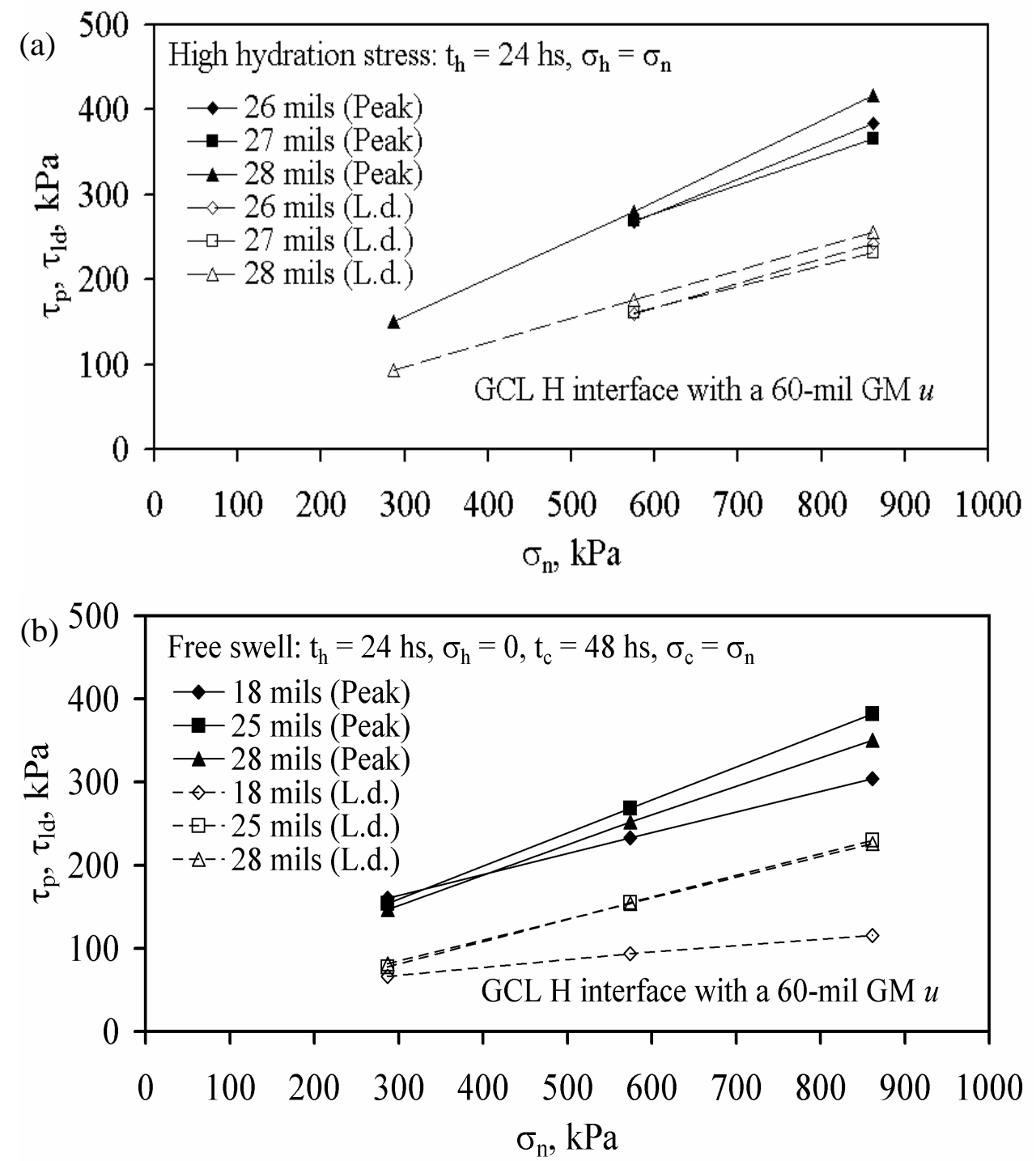

Figure 8: Effect of texturing and GCL conditioning: (a) High hydration normal stress; (b) Free swell

\section{CONCLUSIONS}

GM texturing was observed to improve the shear strength of GCL-GM interfaces. Texturing procedures used by different GM manufacturers were found not to influence GCL-GM interface shear strength. GM texturing, quantified by asperity heights, was found to be highly variable. GM asperity height was found to be a good indicator of the peak shear strength of unhydrated GCL interfaces and clay-GM interfaces tested under the same normal stress. Available information obtained from unhydrated GCL-GM interfaces suggests that asperity heights beyond an optimum asperity heightlead to decreased large -displacement shear strength. 


\section{REFERENCES}

American Society of Testing and Materials. (1998). "Standard Test Method for

Determining the Internal and Interface Shear Resistance of Geosynthetic Clay Liner by the Direct Shear Method." ASTM D6243.

Geosynthetics Research Institute. (1999). "Asperity Measurement of Textured Geomembranes Using a Depth Gage." GRI GM12.

Gilbert, R. B. (2001). "Peak vs. Residual Strength for Waste Containment Systems." Proc. GRI-15, Hot Topics in Geosynthetics II. GSI Publications. pp. 29-39.

Ivy, N. (2003). "Asperity Height Variability and Effects." GFR. October 2003.

Koerner, R.M., and Boman, H.L. (2003). "A Recommendation to Use Peak Shear Strength for Geosynthetic Interface Design.” GFR. April 2003.

McCartney, J.S., Zornberg, J.G., Swan, R., and Gilbert, R.B. (2004). "ReliabilityBased Stability Analysis Considering GCL Shear Strength Variability." Geosynthetics International. In Press.

McCartney, J.S., Zornberg, J.G., and Swan, R.H. (2002). Internal and Interface Shear Strength of Geosynthetic Clay Liners (GCLs). Geotechnical Research Report, Department of CEAE, University of Colorado at Boulder, $471 \mathrm{p}$.

Triplett, E. J., and Fox, P. J. (2001). "Shear Strength of HDPE Geomembrane/Geosynthetic Clay Liner Interfaces.” Journal of Geotechnical and Geoenvironmental Engineering, ASCE, 127(6), 543-552.

Zornberg, J.G., McCartney, J.S., Swan, R.H. (2004). "Internal Shear Strength of Geosynthetic Clay Liners." Journal of Geotechnical and Geoenvironmental Engineering, ASCE. In Press. 